\title{
Renovascular disease: a common cause of secondary hypertension
}

\begin{abstract}
A 56-year-old female patient came at the end of August to the office due to uncontrolled hypertension. Since she was a thin person without a family history of persistant hypertension, suspicion of secondary hypertension was induced and advised for biochemical end imaging tests. The final diagnosis was renovascular hypertension, the most common cause of secondary hypertension. Renal arteriography indicated a $99 \%$ stenosis to the left and the patient underwent a successful stent implantation. After angioplasty, blood pressure returned to normal and the patient did not receive medication. Invasive therapy is recommended for resistant hypertension (at least 4 antihypertensive drugs), aggravation of renal function and patients with flash pulmonary edema or congestive heart failure with preserved ejection fraction $(\mathrm{EF})$.
\end{abstract}

Volume 14 Issue 4 - 202 I

\author{
Chris Kairis,' Stavroula Kamtsiki, ${ }^{2}$ Maria- \\ Eirini Tselegkidi,' George Trellopoulos, ${ }^{3}$ \\ Achilleas Siozopoulos ${ }^{2}$ \\ 'Department of Cardiologist, Aristotle University of \\ Thessaloniki, Greece \\ ${ }^{2}$ Department of Radiologist,Aristotle University of Thessaloniki, \\ Greece \\ ${ }^{3}$ Department of Vascular Surgeon, Aristotle University of \\ Thessaloniki, Greece
}

\begin{abstract}
Correspondence: Chris Kairis, Department of Cardiologist, Aristotle University of Thessaloniki, Greece,
\end{abstract}

Tel00306948595I83,Email chriskairis@hotmail.com

Received: May 24, 202I | Published: July 06, 2021

\section{Introduction}

A 56-year-old female patient came to the office in late August due to uncontrolled hypertension, despite receiving $40 \mathrm{mg}$ of olmesartan and $25 \mathrm{mg}$ of hydrochlrothiazide daily. The clinical history showed that the patient complied with the medication, the hypertension has a recent onset and during the hot summer months there was no remission, as is the case with the majority of Greek patients. In the office her blood pressure was $170 / 100 \mathrm{mmHg}$. As she was a slender individual with no family history of persistent hypertension, secondary hypertension was suspected and further testing with biochemical end imaging tests was suggested.

Urine test did not show albuminuria, while renal function deteriorated in the last six months: urea was increased from 25 to $49 \mathrm{mg}$ / $\mathrm{dl}$ and creatinine from $0.7 \mathrm{mg} / \mathrm{dl}$ to $1.3 \mathrm{mg} / \mathrm{dl}$. In kidney ultrasound the right kidney was at $11 \mathrm{~cm}$ while the left kidney was smaller, at $9.5 \mathrm{~cm}$. The triplex of the renal arteries showed a significant degree of stenosis in the left renal artery (Figures $1 \& 2$ ). The maximum velocity in doppler must not exceed $1.4 \mathrm{~m} / \mathrm{s}$ while our patient has $5 \mathrm{~m} / \mathrm{s}$ in the left artery! Additional pathological findings are: (Figure 3)

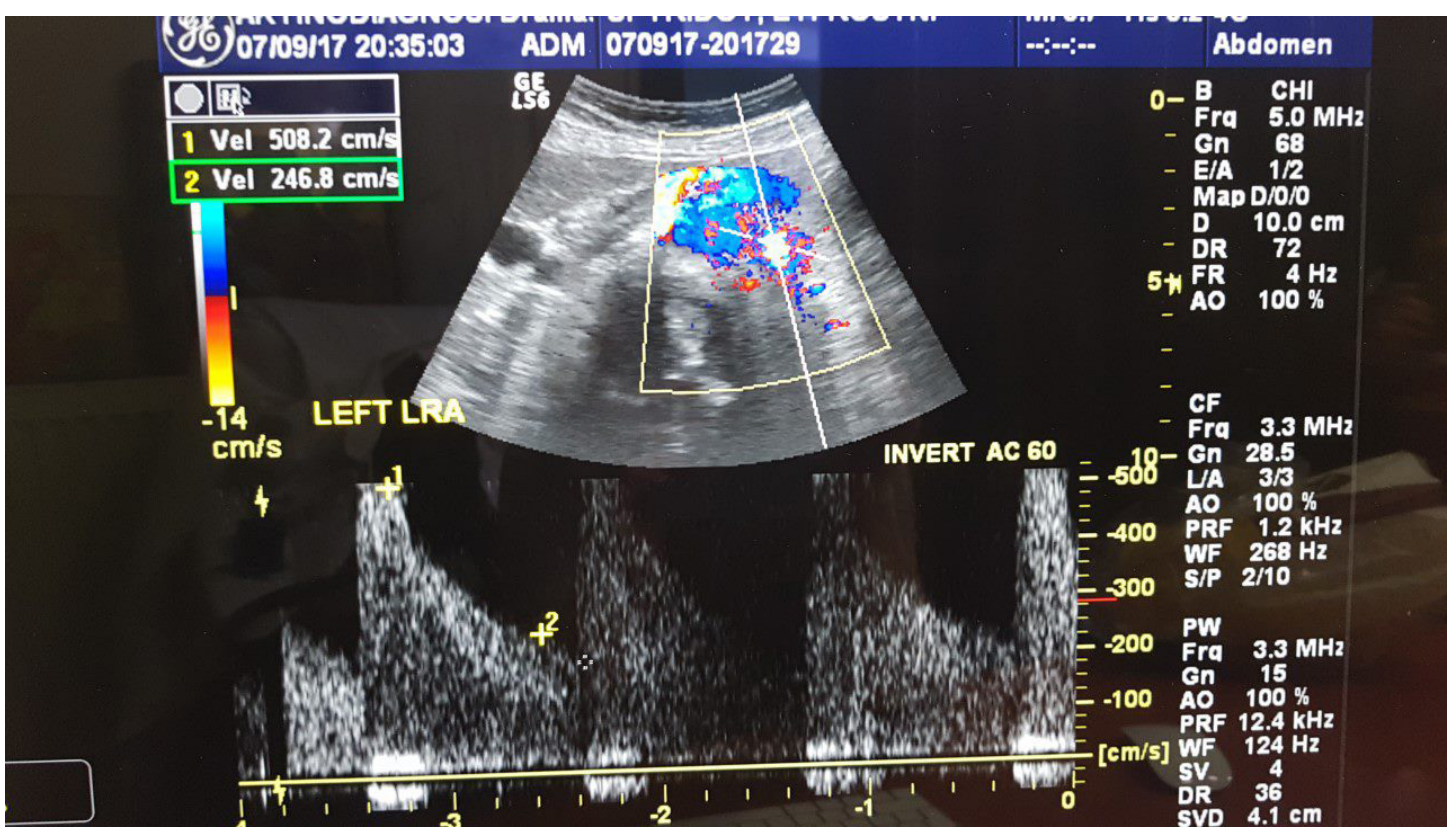

Figure I Doppler of left renal artery. 


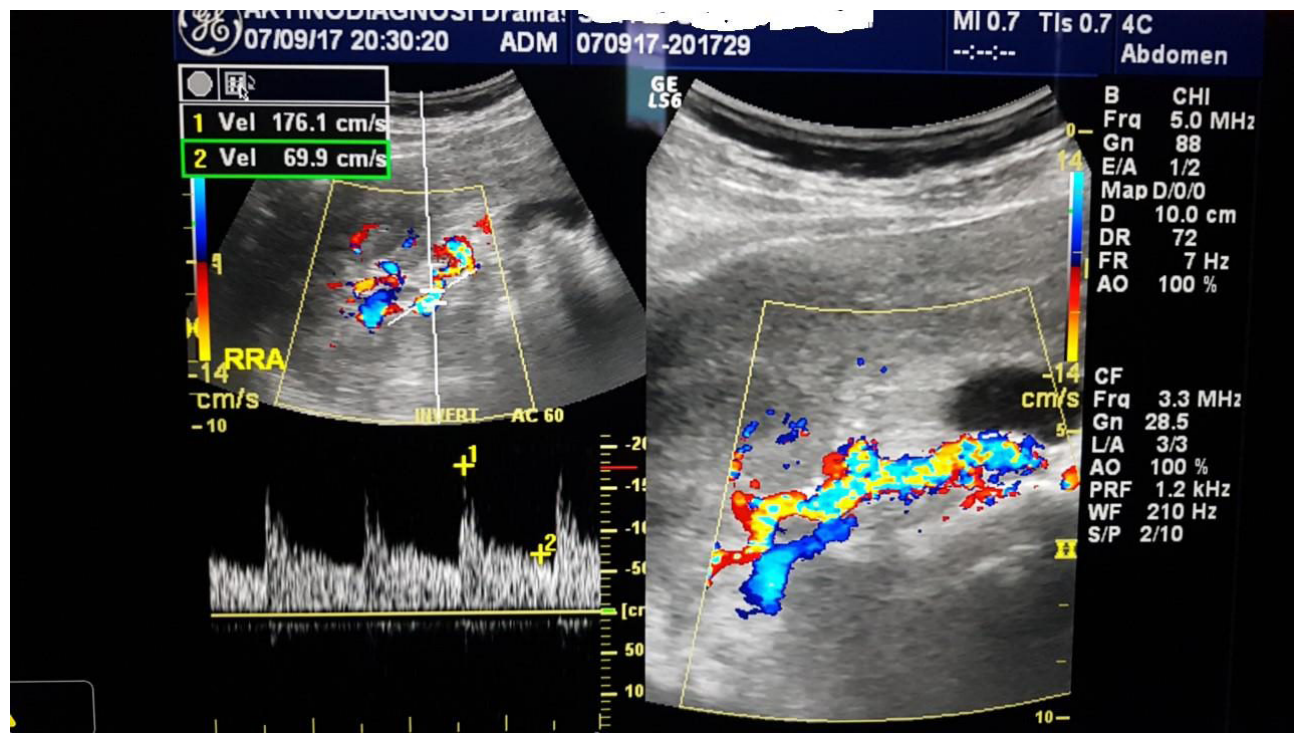

Figure 2 Doppler of right renal artery.
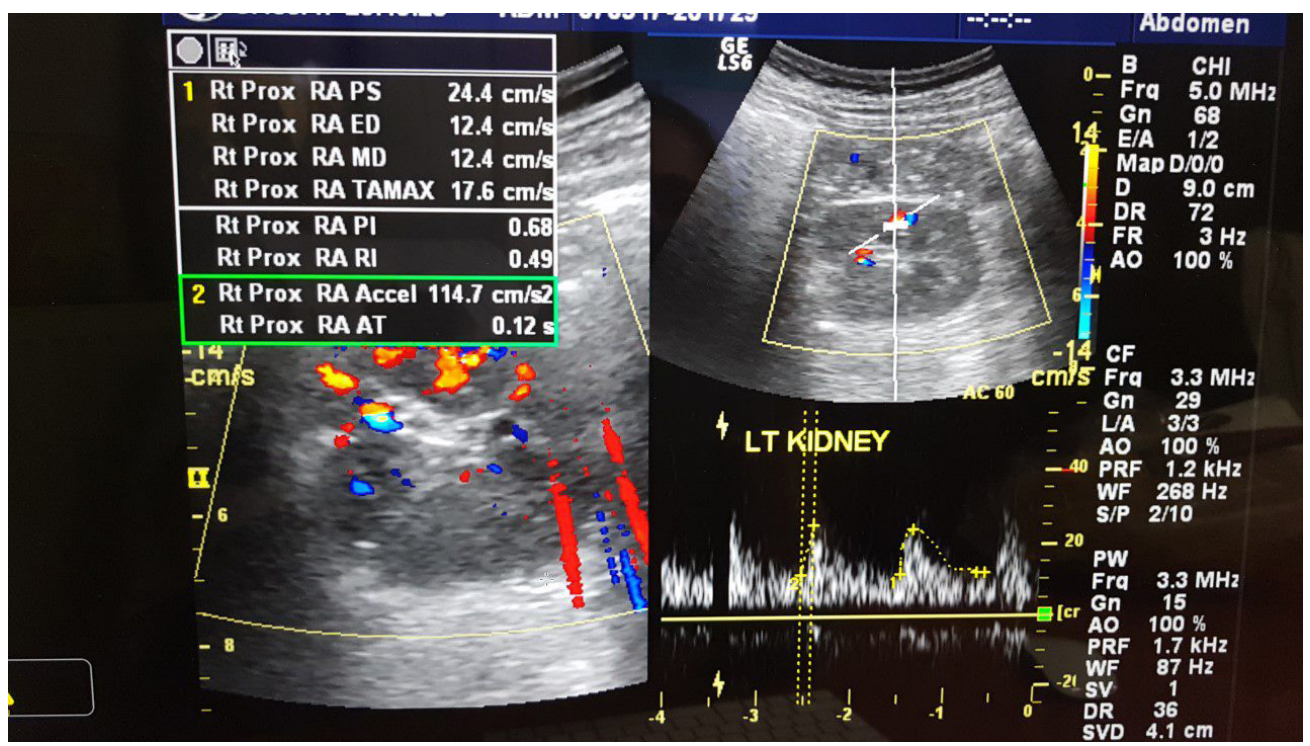

Figure 3 Resistance index and acceleration time of left renal artery.

Resistance index 0.49 (RI:0.6-0.7), is a general indicator of renal parenchymal disease. In patients with severe renal artery stenosis $>75-80 \%$, in the early stages of the disease the resistance index is low $(\mathrm{RI}<0.6)$. Is attributed to marked vasodilation promoted by self-regulating endothelial mechanisms and aimed at protecting the ischemic kidney. As the disease develops and affects the renal parenchyma, the vascular resistance increases and consequently increase $\mathrm{RI}>0.8$. The resistance index has not only diagnostic but also predictive value: $\mathrm{RI}>0.8$ indicates severe parenchymal disease and is an unfavorable indicator of renal function repair and correction of arterial hypertension after reperfusion.

The acceleration time $0,12 \mathrm{~s}(\mathrm{AT}:<0,07 \mathrm{sec})$, indicative renal low flow. The patient was then subjected to magnetic angiography of renal arteries (MRA) confirming the triplex's findings: 90\% stenosis of left renal artery immediately after the outgrowth of the abdominal aorta (Figure 4). In the radioactive nephrogram, impaired left kidney function is demonstrated at $36 \%$ in the relative involvement of total renal function (split function), as opposed to the right kidney that contributes to $64 \%$ of glomerular function (Figure 5). In the same test was calculated with gates technique the GFR in the right kidney at $76.2 \mathrm{ml} / \mathrm{min} / 1,73 \mathrm{~m}^{2}$, while in the left kidney $26.6 \mathrm{ml} / \mathrm{min} / 1,73 \mathrm{~m}^{2}$.

The question arises as to the etiology of renal stenosis: fibromuscular dysplasia or atheromatosis? Fibromuscular dysplasia most commonly affects renal and carotid arteries and is characterized by fibrin deposition on the walls of affected arteries resulting in luminal stenosis. FMD also is related to aneurysms, segregations and helical vessels.

The findings suggest atherosclerosis:

1. From the clinical history, the patient is 56 years old and a smoker, while FMD affects younger ages.

2. In the triplex of abdominal aorta, atherosclerotic lesions and wall thrombus are present.

3. In MRA of renal arteries there is no characteristic nodular Figure of FMD (string-of-beads, areas of relative stenoses alternating with small aneurysms). 


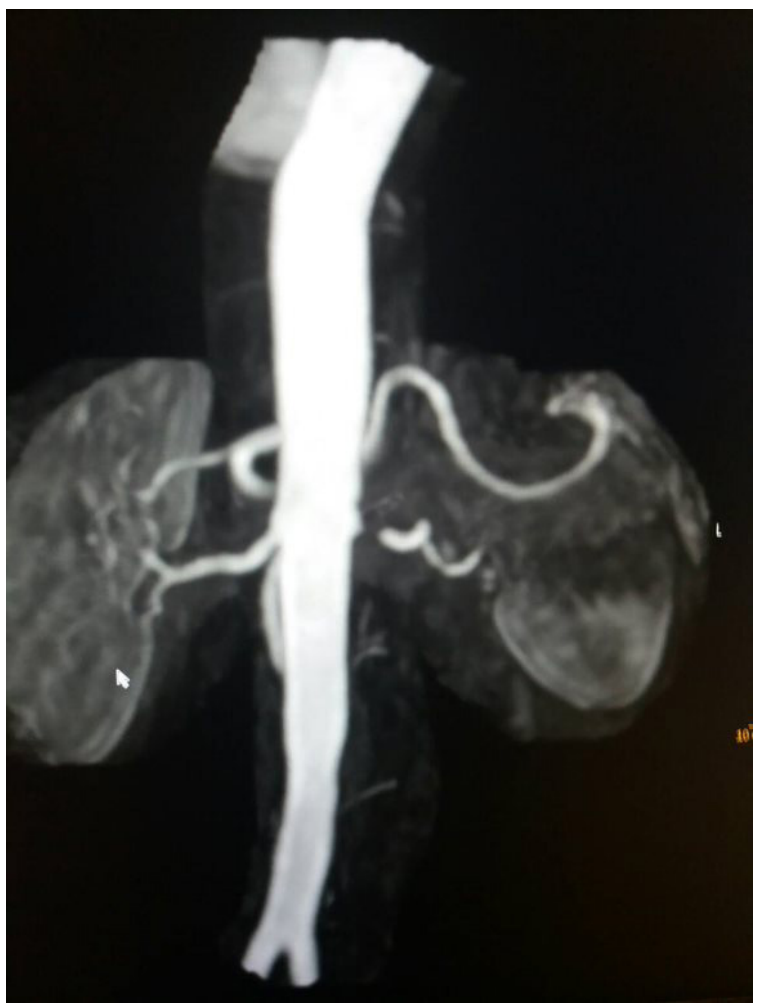

Figure 4 MRA, severe stenosis of left renal artery.

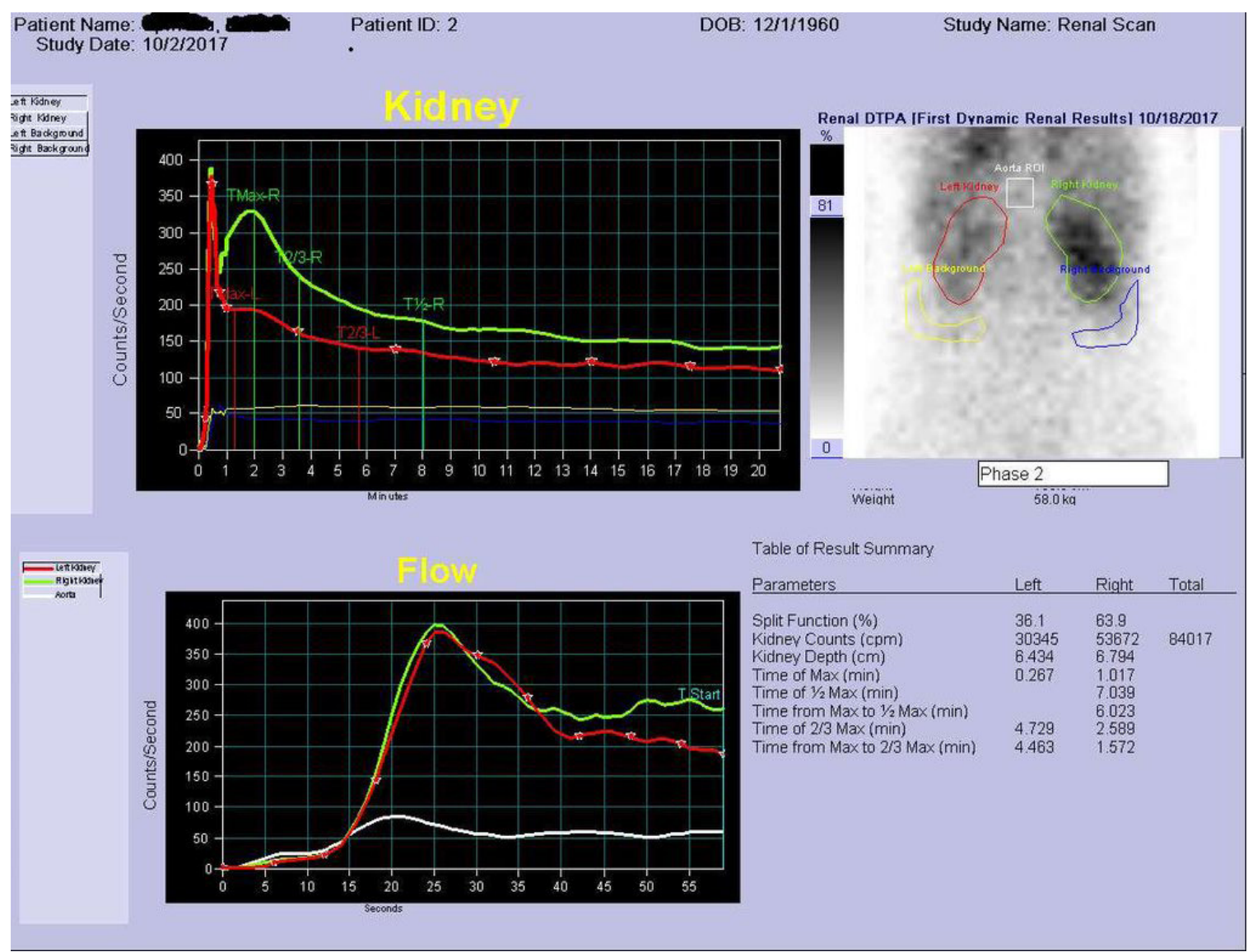

Figure 5 Radioactive nephrogram.

Citation: Kairis C, Kamtsiki S,Tselegkidi ME, et al. Renovascular disease: a common cause of secondary hypertension.J Cardiol Curr Res. 2021;14(4):75-80. DOI: I0.15406/jccr.202I.14.005I5 
An additional element is the localization of the stenosis in the initial part of renal vessel, as opposed to FMD that commonly affects the middle and peripheral portions. The sudden deterioration of renal function within a short period of time also advocates for atherosclerosis as the FMD has a slower course. It is noted that atherosclerosis may lead to complete abstraction/thrombosis over time, rarely occurring FMD. Finally, the immunological test performed to rule out vasculitis was negative. Renal arteriography indicated a $99 \%$ stenosis to the left and the patient underwent a successful stent implantation. After angioplasty, blood pressure returned to normal and the patient did not receive any medication. It is worth noting that despite the presence of stage III hypertension and the underlying disease, the patient did not show signs of diastolic dysfunction in the Doppler (Figures 8-10), nor any signs of hypertrophic left ventricle in ECG. Not a patient with long-standing uncontrolled hypertension. Moreover, to stress echocardiography with doboutamine there were no wall motion abnormalities, while coronary flow reserve was normal (CFR $\mathrm{LAD}=2.2$ ) (Figure 11A \& 11B).

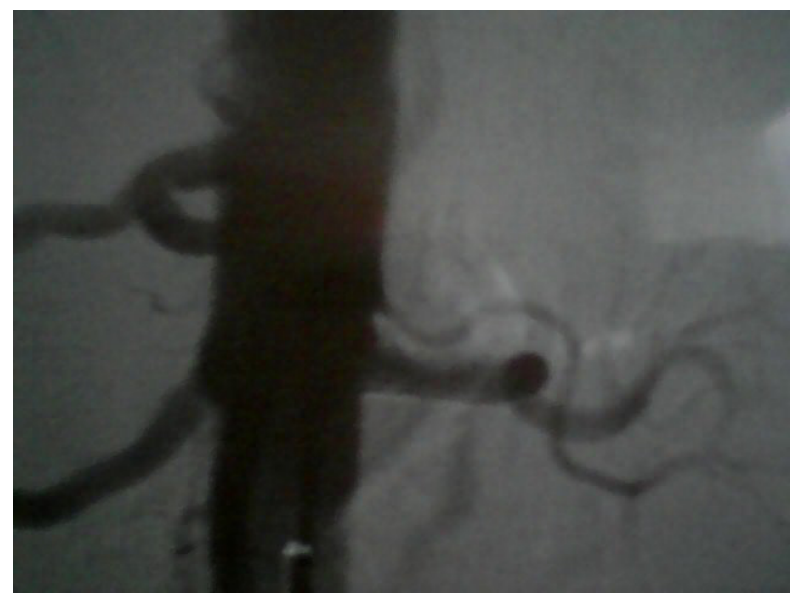

Figure 6 Renal angiography after stent implantation.

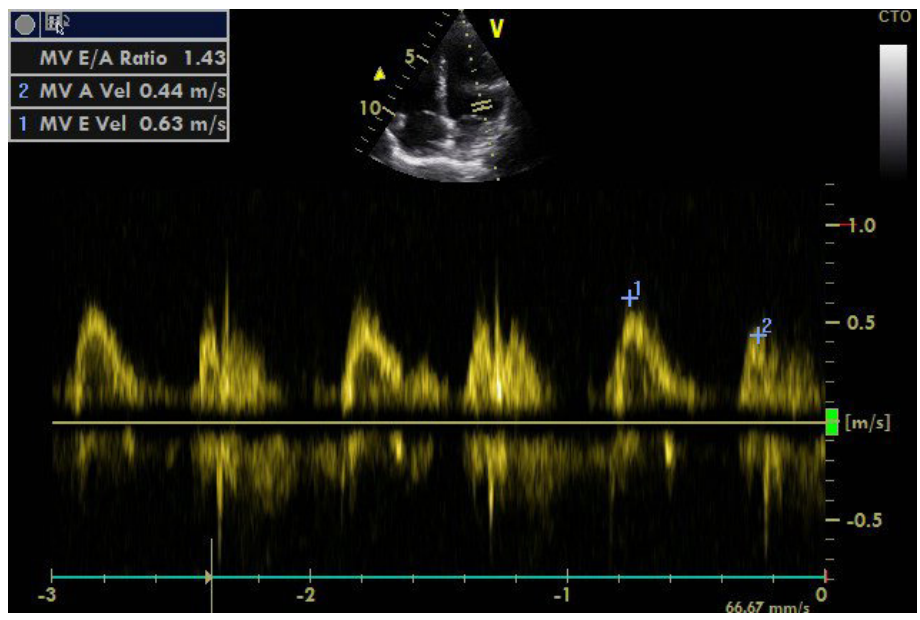

Figure 7 Doppler of mitral valve inflow.

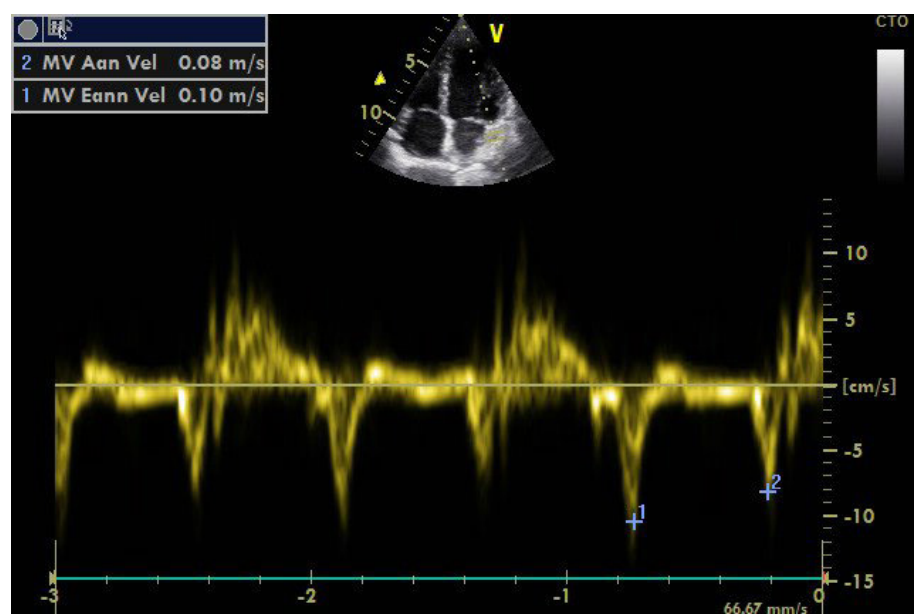

Figure 8 Tissue Doppler of mitral annulus. 


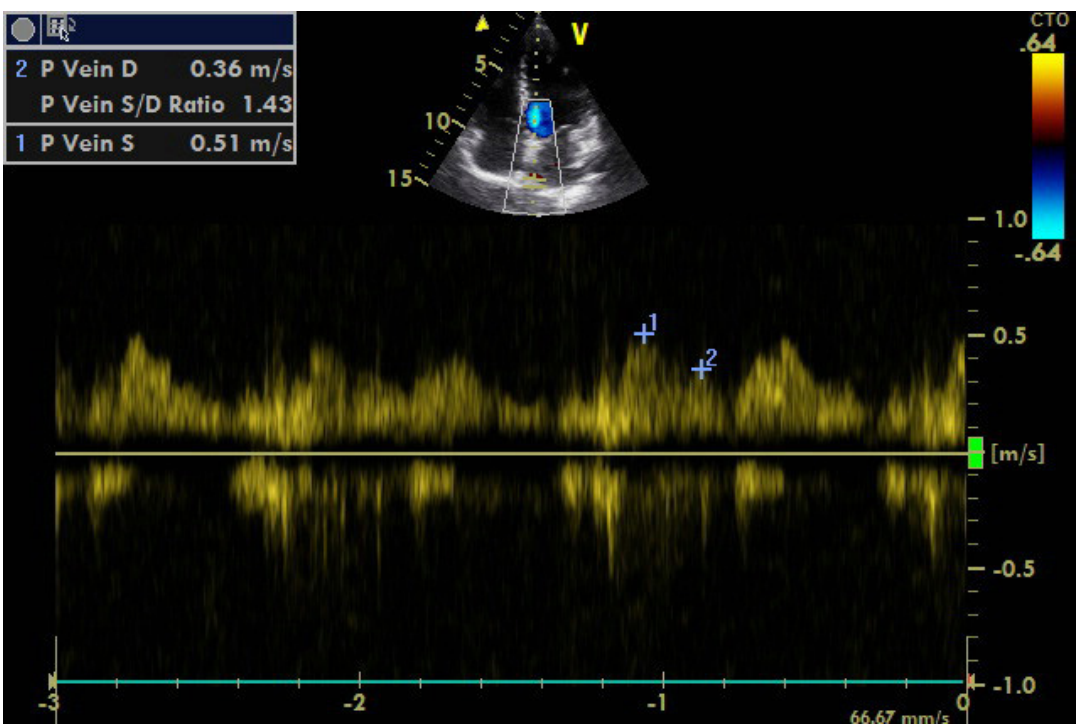

Figure 9 Doppler of pulmonary vein flow.

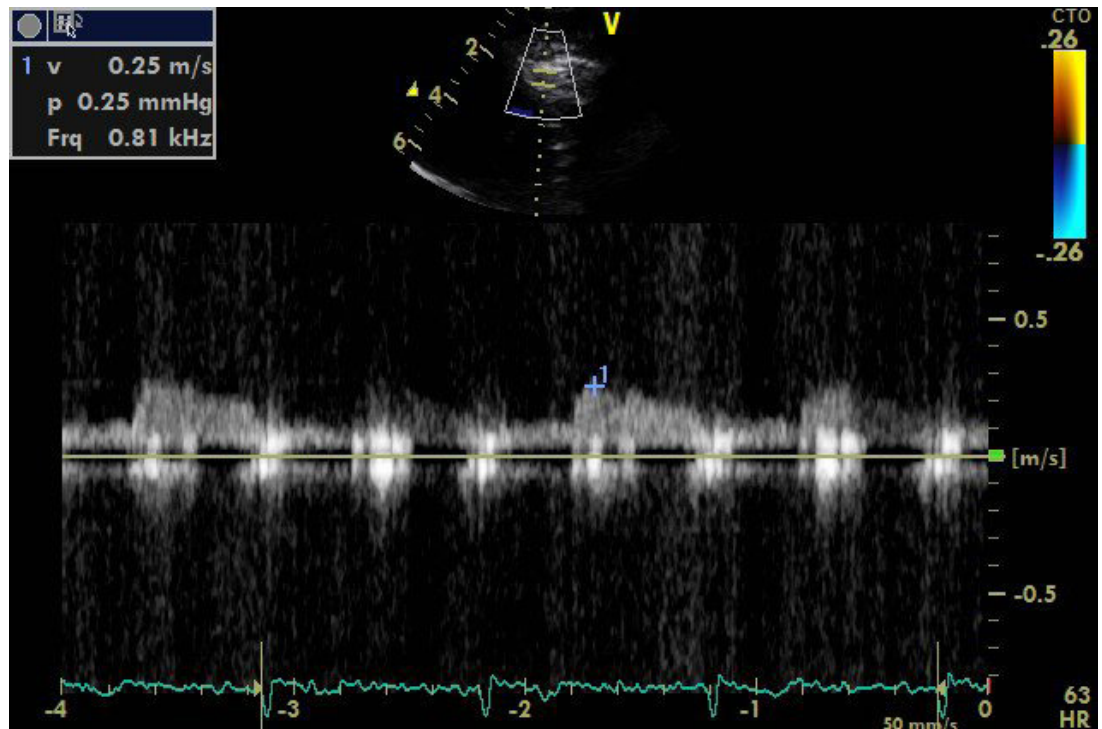

Figure I0A Coronary flow reserve LAD, basal flow.

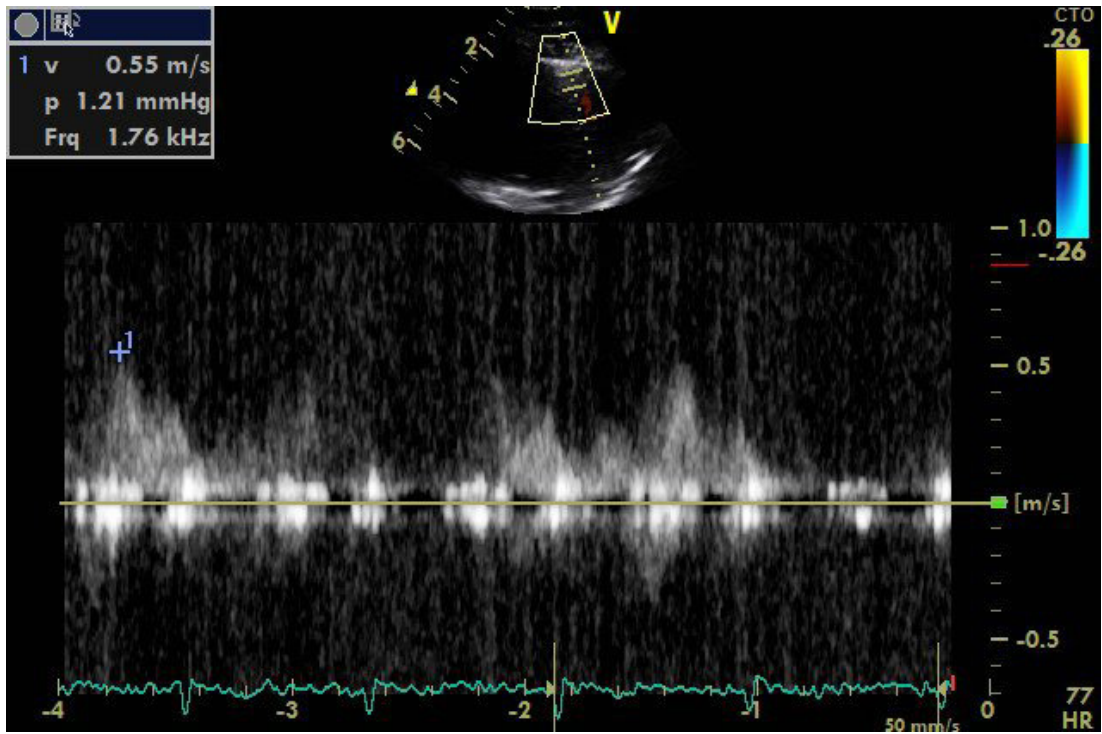

Figure IOB Coronary flow reserve LAD, hyperemic flow after adenosine infusion.

Citation: Kairis C, Kamtsiki S, Tselegkidi ME, et al. Renovascular disease: a common cause of secondary hypertension.J Cardiol Curr Res. 202I;14(4):75-80. DOI: 10.15406/jccr.202I.14.005I5 
Renovascular hypertension is the most common cause of secondary hypertension. Clinical suspicion will lead to further control in the following patients:

a. Hypertension before the age of 30years old

b. Resistant hypertension with renal or heart failure

c. Murmor in the abdominal aorta

d. Rapid aggravation of pre-existing well-controlled hypertension

e. Resistant hypertension, such as uncontrolled hypertension despite the receipt of 4 anti-hypertensive Drugs,including antimineralcorticoid

f. Hypertensive crisis, ie acute renal failure, pulmonary edema, hypertensive encephalopathy

g. Aggravation of renal function following use of drugs blocking the renin -angiotensin-aldosterone system

h. Unexplained kidney atrophy or difference in kidney size

i. Flash pulmonary edema

Beyond atheromatosis and fibromuscular dysplasia but more rarely are:
a. Vasculitis (Burger,Takayasu,polyarteritis nodosa)
b. Dissection of the aorta or renal artery
c. Injury of renal artery
d. Thrombus embolism
e. Fibrin disease
f. Stenosis after radiation therapy

With regard to medication in patients with RAS: calcium antagonists b-blockers and diuretics are recommended with level I according to the latest guidelines ESC 2017. ACE and blockers of angiotensin receptors are recommended in heterogeneous stenosis with level I (ESC 2017).

Invasive therapy is recommended for resistant hypertension (at least 4 antihypertensive drugs), aggravation of renal function and patients with flash pulmonary edema or congestive heart failure with preserved EF. Interventional treatment includes intravascular rehabilitation and surgical treatment, aimed at reperfusion of the kidney. Surgical treatment is recommended when complex anatomy (renal artery aneurysm, bifurcation), failure of intravascular therapy or when an open surgery of the aorta are present. Intravascular treatment involves the use of the balloon expandable stent. The balloon preloaded stent is placed at the stenosis at the same time as angioplasty. The other technique is to imitate the balloon and implant the stent later.
The large randomized clinical trials (ASTRAL 2007 and CORAL 2014) did not show any benefit in improving renal function in patients with RAS who underwent renal artery angioplasty as routine treatment. In Coral study a mild decrease in blood pressure was observed by $23 \mathrm{mmHg}$ in the group of angioplasty $(\mathrm{p}=0.03)$.

It is understood that the universal application of renal artery angioplasty as first-line therapy does not yield results. Therefore, the appropriate patient selection is appropriate, based not only on anatomical data (renal triplex arthritis, MRA or CTA) but also on functional criteria, as derived from successive measurements of creatinine clearance and of the radioactive nephrogram. Regular clinical examination is of major importance for patients and systematic monitoring of blood pressure, therefore patients with persistent hypertension (at least 4 antihypertensive drugs) can undergo angioplasty in time and avoid renal parenchymal lesions.

\section{Acknowledgments}

None

\section{Conflicts of interest}

Author declares there are no conflicts of interest.

\section{Funding}

This manuscript was not supported by any funding.

\section{References}

1. Aboyans V, Ricco JB, Bartelink MLEL, et al. 2017 ESC Guidelines on the Diagnosis and Treatment of Peripheral Arterial Diseases, in collaboration with the European Society for Vascular Surgery (ESVS): Document covering atherosclerotic disease of extracranial carotid and vertebral, mesenteric, renal, upper and lower extremity arteriesEndorsed by: the European Stroke Organization (ESO)The Task Force for the Diagnosis and Treatment of Peripheral Arterial Diseases of the European Society of Cardiology (ESC) and of the European Society for Vascular Surgery (ESVS). Eur Heart J. 2018;39(9):763-816.

2. Persu A, Giavarini A, Touzé E, et al: European consensus on the diagnosis and management of fibromusular dysplasia. $J$ Hypertens. 2014;32(7):1367-1378,

3. Tafur Soto JD, White CJ. Renal artery stenosis. Cardiol Clin. 2015;33(1):59-73.

4. Khoury MH, Gornik HL. Fibromuscular dysplasia (FMD). Vasc Med. 2017;22(3):248-252.

5. Cooper CJ, Murphy TP, Cutlip DE, et al. Stenting and Medical Therapy for Atherosclerotic Renal-Artery Stenosis. N Engl J Med. 2014;370(1):1322.

6. Wheatley K, Ives N, Gray R, et al. Revascularization versus medical therapy for renal-artery stenosis. $N$ Engl J Med. 2009;361(20):19531962. 